\section{Trauma Surgery} \& Acute Care Open

\title{
Damage control open mediastinum in the management of penetrating cardiac injury
}

\author{
Peng Yu, Ashley Levine, Weidun Guo
}

Department of Surgery, University at Buffalo Jacobs School of Medicine and Biomedical Sciences, Buffalo, New York, USA

\section{Correspondence to} Dr Weidun Guo, Department of Surgery, University at Buffalo Jacobs School of Medicine and Biomedical Sciences, Buffalo, NY 14215, USA; waguo@buffalo. edu
(C) Author(s) (or their employer(s)) 2021. Re-use permitted under CC BY-NC. No commercial re-use. See rights and permissions. Published by BMJ.

To cite: Yu P, Levine A, Guo W. Trauma Surg Acute Care Open 2021:6:e000812.

\section{CASE DESCRIPTION}

A woman in her early 30s presented to a level 1 trauma center with a single through-and-through gunshot wound to the lower sternum and left posterior chest. She was hypotensive and tachycardic on arrival. Physical examination and chest X-ray suggested left hemothorax. An emergent left tube thoracostomy drained $200 \mathrm{~mL}$ of fresh blood. A focused assessment with sonography for trauma was equivocal for hemopericardium, while demonstrating a trace amount of fluid in the left upper abdomen. A massive transfusion protocol was initiated and she was taken to the operating room for an emergent median sternotomy due to a high suspicion for cardiac injury and an intra-abdominal involvement. Intraoperatively, a $3 \mathrm{~cm}$ right ventricle laceration was identified and a cardiorrhaphy was performed. Intrathoracic cardiac massages were necessitated due to asystole. The patient's abdomen was noted more distended and firmer, and the bullet trajectory was identified coursing into the abdomen. A subsequent exploratory laparotomy revealed hemoperitoneum, liver laceration, and spleen laceration. These injuries required a splenectomy, liver packing, and negative-pressure abdominal packing. The patient received 47 units of packed red blood

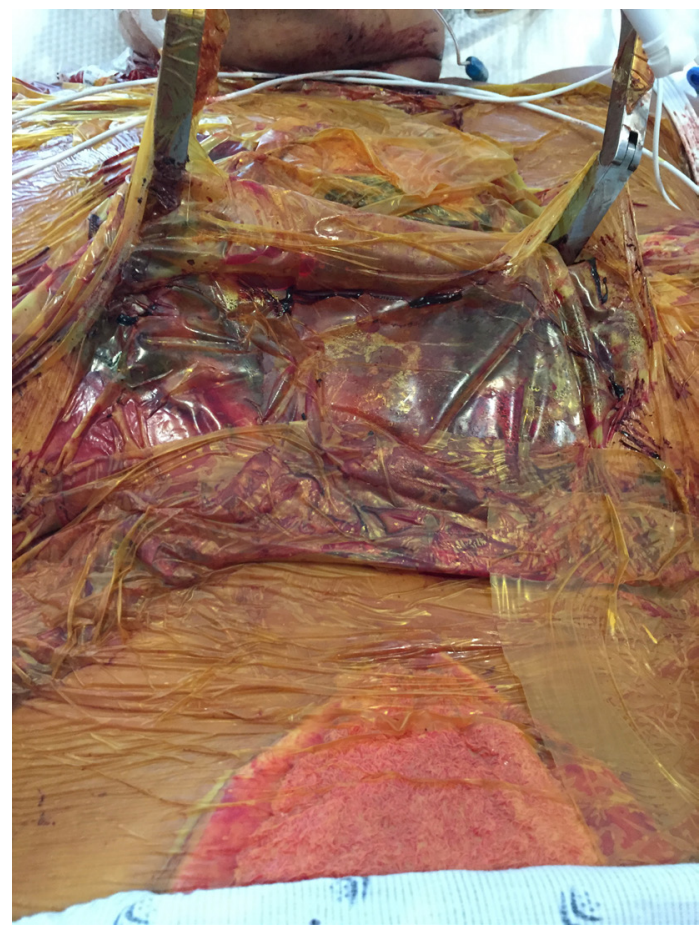

Figure 1 The sternotomy wound with a stay sternal retractor and an occlusive dressing.

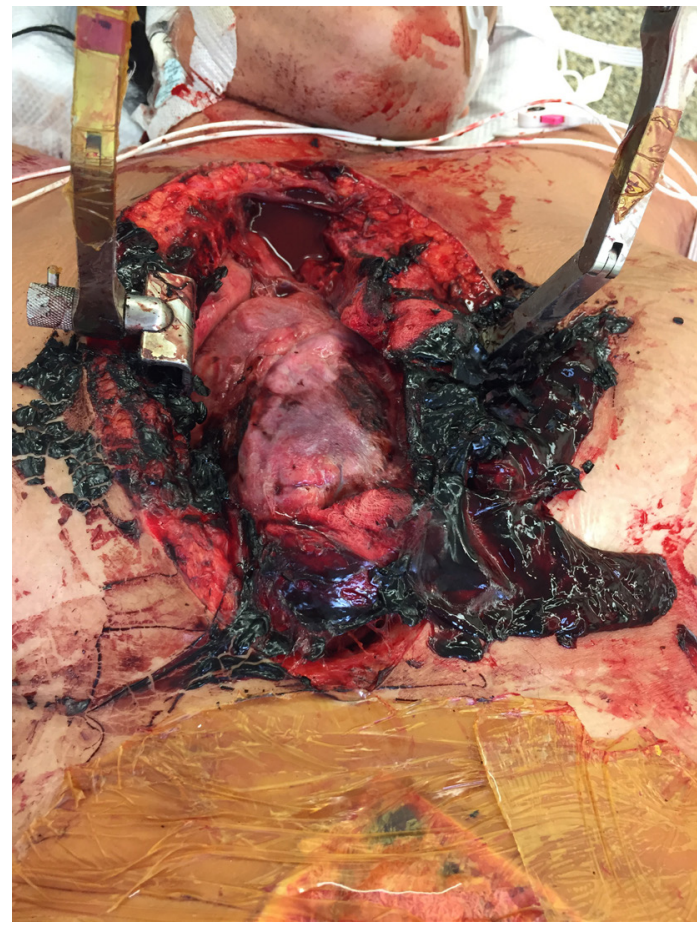

Figure 2 The sternotomy wound during the first reexploration. Blood clots were noted in the mediastinum.

cells, rationed with fresh frozen plasma and platelets. She became coagulopathic, hypothermic, and acidotic due to the profound hemorrhage and the complexity of multi-trauma. The heart, lungs and chest wall were tremendously edematous. When the sternotomy incision was approximated, she became severely hypotensive.

\section{WHAT WOULD YOU DO?}

A. Mediastinal skin closure alone with suture, towel clips, or skin zipper.

B. An en masse closure taking the thoracic cage, muscles and skin in a running interlocking suture.

C. Open mediastinum with a negative-pressure wound dressing.

D. Moist dressing for the open mediastinal wound with frequent antibiotics irrigation postoperatively.

\section{WHAT WE DID AND WHY}

Correct answer: C.

Options A and B provide a better closure minimizing the risk of infection. However, these methods carry a risk of increasing intrathoracic pressure, which negates the benefits of damage 


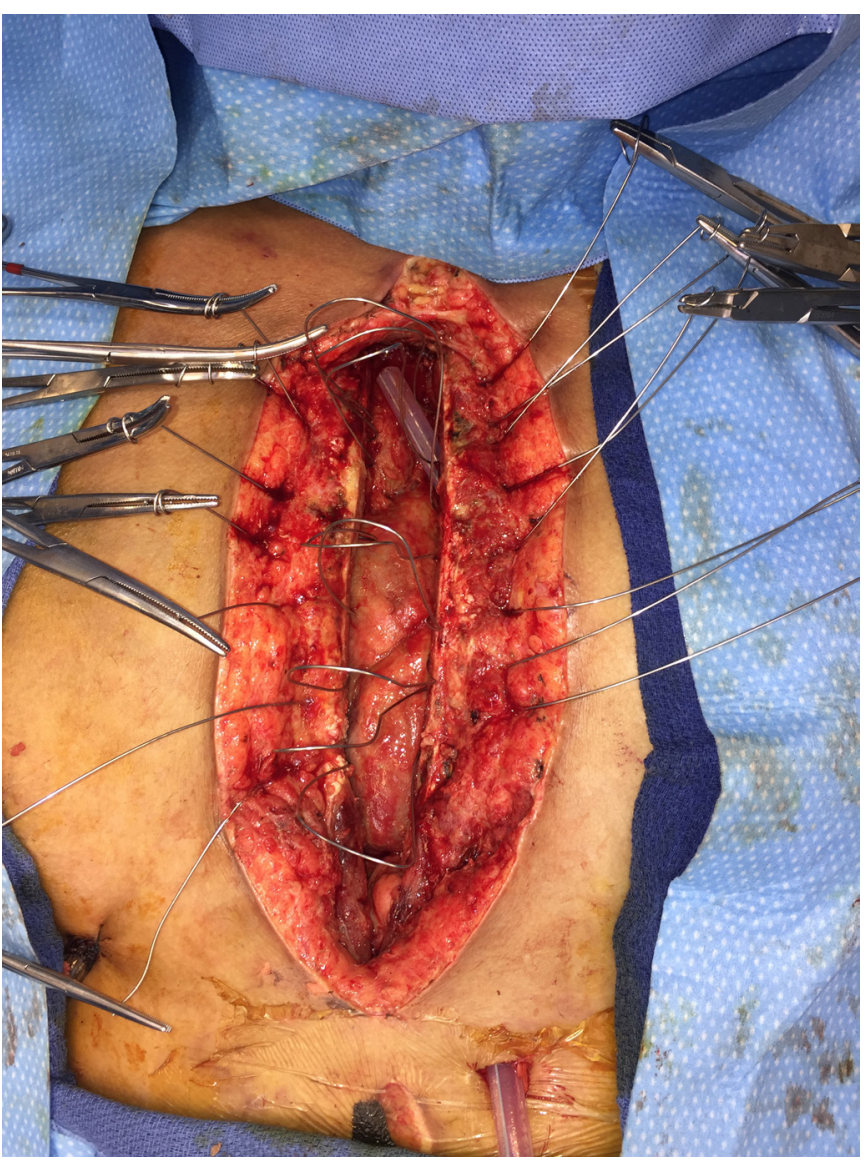

Figure 3 The sternotomy wound was safely closed 5 days after the initial surgery.

control open mediastinum (DCOM). Option D carries a higher risk of infection.

In our case, the mediastinum was kept open with a stay sternal retractor to avoid cardiac compression. Two mediastinal chest tubes were placed. A non-adhesive plastic warmer drape was placed first to separate the heart from the moist gauze. The mediastinal incision was then covered with a sterile adhesive drape (figure 1). Finally, a negative-pressure dressing was applied to the open abdomen. The patient was transferred to the intensive care unit (ICU) for further resuscitation and physiological stabilization. She subsequently underwent three mediastinal dressing changes in the operating room (figure 2) and a definitive closure of the sternotomy on hospital day 6 (figure 3). She additionally underwent three abdominal re-explorations with a fascial closure. Major postoperative complications included mediastinitis requiring a 3 -week course of broad-spectrum antibiotics, ventilator-associated pneumonia requiring prolonged mechanical ventilation with a tracheostomy, and acute renal failure without the need for hemodialysis. The patient was discharged to a rehabilitation facility 47 days after injury (ICU length of stay: 41 days).

DCOM has been described in $1 \%$ to $4 \%$ of elective adult cardiac operations in numerous publications. However, its potential in trauma setting has been much less recognized or published. Our reasoning for applying DCOM with subsequent delayed sternal closure (DSC) was twofold. First, it necessitated a damage control approach intraoperatively. The damage control principle of abbreviating procedural duration with planned re-exploration has demonstrated improvements in survival rates of severely injured patients with the lethal triad of metabolic acidosis, hypothermia, and coagulopathy. In our case, by the time the cardiac and intra-abdominal injuries were adequately addressed, the patient had manifested this classic lethal triad, leaving open mediastinum and open abdomen as the best strategy for patient survivability. Second, there was a high risk of intrathoracic/mediastinal compartment syndrome. Mediastinal compartment syndrome is typically caused by myocardial edema, acute ventricular dilatation, and pulmonary and chest wall edema. These changes subsequently raise the mediastinal pressure, leading to an increased peak inspiratory pressure and decreased cardiac output with hemodynamic collapse. DCOM provides not only an additional space for the edematous heart, but also a rapid and easy access to the heart and mediastinum for evacuation of hematoma or control of bleeding, if any.

Given the higher risk of mediastinitis and mortality associated with a prolonged DCOM, the chest should be closed as soon as the initial indications have resolved and the patient is hemodynamically stable. Although there is still no clinical trial to verify its efficacy, our practice, based on experiential evidence, is that DCOM patients should receive antibiotic prophylaxis until a definitive closure.

In conclusion, our case demonstrates that DCOM-DSC is a practical option for penetrating cardiac injury manifesting mediastinal compartment syndrome. This should be in the surgeon's armamentarium in the management of penetrating cardiac injuries.

Contributors PY was responsible for literature review, article drafting and revisions. AL was responsible for literature review and article revisions. WG was responsible for project conception and article revisions. All authors approved of the final article version.

Funding The authors have not declared a specific grant for this research from any funding agency in the public, commercial or not-for-profit sectors.

Competing interests None declared.

Patient consent for publication Not required.

Provenance and peer review Not commissioned; internally peer reviewed.

Open access This is an open access article distributed in accordance with the Creative Commons Attribution Non Commercial (CC BY-NC 4.0) license, which permits others to distribute, remix, adapt, build upon this work non-commercially, and license their derivative works on different terms, provided the original work is properly cited, appropriate credit is given, any changes made indicated, and the use is non-commercial. See: http://creativecommons.org/licenses/by-nc/4.0/. 